\title{
Leticia Cossettini: la mujer detrás de la maestra
}

\author{
Leticia Cossettini: the Woman Behind the Teacher
}

Micaela Pellegrini Malpiedi ${ }^{1}$

\section{Resumen}

\begin{abstract}
Este artículo se ubica dentro de la línea de la historia de la educación con mujeres en perspectiva de género y tiene por cometido profundizar el estudio de las trayectorias de vida de maestras argentinas durante el siglo XX. Este objetivo persigue una hipótesis central la cual sostiene que, a lo largo de los años, la experiencia particular de mujeres docentes ha quedado oculta detrás de la Escuela y su lógica institucional moderna. Tal ha sido el caso de Leticia Cossettini. Ésta, fue una versátil maestra que, ocupó un lugar preponderante dentro del proyecto educativo escolanovista Escuela Serena (1935-1950), dicha pertenencia institucional obturó conocer su singularidad: al tiempo que fue reconocida como la señorita Leticia se invisibilizó la Leticia artista y escritora de libros.
\end{abstract}

\section{Palabras clave: maestras, antibiografía, escuela, escritura, arte.}

\section{Abstract}

This article is located in the context of history of education about women, and from a gender perspective. Its aim is to deepen the study of the life of Argentinian female teachers during the 20th century. The focus of this perspective relies on the assumption that, over the years, the experience of these women as individuals has remained hidden behind the School and its modern institutional logic. Such has been Leticia Cossettini's case: a versatile teacher who had an important place inside the New School educational project "Escuela Serena" (1935-1950). Anyhow, her attachment to this project hindered her singularity because, at the time she was recognized as Miss Leticia, her contributions to art and writing were made invisible.

\section{Keywords: Teachers, Antibiography, School, Writing, Art.}

\footnotetext{
${ }^{1}$ ISHIR/CONICET-UNR. Licenciada en Ciencias de la Educación. Profesora en Ciencias de la Educación (UNR) y Doctoranda en Ciencias de la Educación (UBA). Sus líneas de investigación son la Historia de la Educación con mujeres en perspectiva de género. Correo electrónico: micaelapellegrini89@gmail.com.
} 


\section{Introducción}

¿Quién fue Leticia Cossettini? Esta mujer nació en Argentina, en 1904 en la ciudad santafesina de San Jorge y murió en el año 2004 en Rosario. Integrante de una familia ordenada en las claves del patriarcado de clase media y siendo la quinta de seis hermanos (cuatro mujeres y dos varones), fue poseedora de un capital cultural aportado por su padre: don Antonio Cossettini. Este, fue docente inmigrante italiano, integró importantes y distinguidas instituciones de la ciudad de Rafaela (Santa Fe) y otras localidades aledañas, entre ellas la "Logia la Antorcha". Este hecho le proporcionó al apellido "Cossettini", un símbolo de prestigio y compromiso social y político. En efecto, esta fuerte impronta influyó en la decisión de Leticia por la docencia. La misma, al igual que sus hermanas mujeres, estudió magisterio en una escuela normal.

Leticia no ha sido la única mujer que decidió formarse como maestra durante las primeras décadas del siglo XX en Santa Fe, ${ }^{2}$ Argentina. Sin embargo, a diferencia de muchas de sus congéneres, perteneció a un grupo de maestras que desafiaron los principios de la pedagogía normalista y se alineó al movimiento de escuela nueva. A partir de ese entonces, comenzó a trabajar con su hermana mayor, Olga Cossettini, reconocida pedagoga con quien compartió los espacios de trabajo escolar. Primero, en la Escuela Serena de Rafaela (Escuela Normal Domingo de Oro - entre 1930 y 1935) y, segundo, en la Escuela Serena de Rosario (Escuela Gabriel Carrasco No69 - entre 1935 y 1950). ${ }^{3}$

En ambas experiencias educativas, al igual que otros integrantes del movimiento escolanovista, Leticia promulgó postulados relacionados con el desarrollo intelectual, moral y social del niño y la niña como propósito educativo, posicionando las necesidades de sus estudiantes como centrales a la hora de seleccionar el contenido y actividades. El carácter experimental de la Escuela Serena, le permitió seguir caminos originales que, en este caso, incluyeron el arte como un eje transversal que atravesó todos los momentos escolares: los recreos, paseos, misiones culturales, asignaturas y el aula (Pellegrini, 2016). El arte en todas sus manifestaciones: danza, pintura, canto, escultura, teatro, poesía, etc. Estos niños y niñas,

\footnotetext{
2 Existe una cuantiosa bibliografía que referencia el "proceso de feminización de la docencia" en Argentina (al menos las provincias del centro del país), que destacan la preponderancia de mujeres en el ingreso a las Escuelas Normales para estudiar magisterio y a posteriori ejercer la docencia (Yannoulas, 1996; Morgade, 1997).

${ }^{3}$ La Escuela Serena ha sido una experiencia escolanovista materializada en la "Escuela Carrasco" № 69, Rosario. Durante los años 1935 a 1944 la Escuela funcionó con las particularidades de una educación escolanovista; luego de esa fecha, las autoridades provinciales retiraron el carácter experimental de la obra de Olga. No obstante, para esos años las hermanas debieron atravesar por momentos difíciles: en 1950 llegó la cesantía de las protagonistas, Olga y Leticia fueron echadas. Esta experiencia ha sido arduamente estudiada por la historiografía argentina sostenida en abordajes teórico-metodológicos y preguntas diferentes. Se recomienda la consulta de la siguiente bibliografía: Marcela Pelanda (1995); Sandra Carli (2002); Pablo Colotta (2002) Adriana Puiggrós (1993); Edgardo Ossanna, (1993); María del Carmen Castells (2008); Adriana Puiggrós Roberto Marengo (2013); Fernández, et. al. (2014); Fernández y Caldo (2013); Díaz y Serra (2009); (Caldo, 2018).
} 
lejos de operar desde una lógica contemplativa y memorística, fueron instados por su maestra a ponerle el cuerpo al arte y, como derivado de ella, al aprendizaje en general.

Leticia fue maestra de aula y en esta lógica es necesario analizar su vida a partir del "programa institucional moderno" (Dubet, 2010). De acuerdo a la teoría sociológica de Françis Dubet, las instituciones modernas (entre ellas las escuelas), operaron sobre los sujetos mecanismos de invisibilización. La Escuela fue entendida como un santuario laico incuestionable y transmisora de valores y conocimientos sagrados. Ese fue el gesto que maniobró las individualidades de las maestras. Los rasgos identitarios que hicieron a la personalidad de las mujeres que enseñaron en las escuelas modernas, fueron desdibujadas bajo las estructuras de un proyecto pedagógico específico que legitimó sus vidas bajo el sustantivo colectivo "maestras" (Billorou, 2016). En este sentido, Leticia Cossettini quedó bajo el nombramiento de "señorita Leticia" y un conjunto de elementos culturales que hicieron al rol docente. Los saberes y valores transmitidos, la vestimenta obligatoria, la caligrafía, el porte corporal, las relaciones jerárquicas escolares, oficiaron como efectos antibiográficos (Terradas, 1992) de las trayectorias desarrolladas por Leticia tanto dentro como afuera de la Escuela Serena. Este último concepto se tomó como referencia del libro que se titula Eliza Kendal. Reflexiones sobre una antibiografía, cuya autoría le pertenece a Ignaci Terradas (1992). Su estudio invita a reflexionar sobre los motivos sociales, culturales y de género que condicionan la posibilidad de biografiar o no a distintos sujetos. Lo que el autor advierte es que, a partir de la antibiografía, se pueden reconocer las características de época, en tanto lo que se oculta de los sujetos hablan de los valores, estereotipos y condicionamientos contextuales. Un claro ejemplo resulta la vida de Leticia Cossettini, a quien siendo escritora de libros didácticos y productora de objetos artísticos (incursionó en el mundo de las acuarelas y otras manualidades impregnando de nombre propio diversas obras y galerías de arte), solo se la recuerda como "la señorita Leticia".

A continuación se correrá ${ }^{4}$ el efecto antibiográfico que el rol docente ejerció sobre la vida de Leticia y se describirá parte de su trayectoria por fuera del trabajo áulico. Así, poco a poco, irá apareciendo la mujer que se encuentra detrás de la maestra y, en ese ejercicio, aparecerán también las limitaciones y condicionamientos culturales de época con los que Leticia debió batallar para poder proyectarse como escritora didáctica y productora de objetos de arte.

\footnotetext{
${ }^{4}$ Este trabajo será realizado a partir del análisis de sus dos libros de autoría, Teatro de Niños (1947) y Del Juego al Arte Infantil (1977), sus producciones artísticas y artículos periodísticos que llevan su nombre. Todo este material se encuentra en el Archivo Pedagógico Cossettini. El mismo se encuentra en el IRICE (CONICET/ UNR) -Instituto Rosario de Investigaciones en Ciencias de la Educación en la ciudad de Rosario (Santa Fe, Argentina) y se encuentra conformado por materiales resguardados y a posteriori donado por las propias hermanas Cossettini (Pellegrini, 2019). También se utilizaron entrevistas semiestructuradas realizadas por la autora de este artículo hacia ex alumnos y vecinas de Leticia.
} 


\section{Leticia y su trayectoria en el campo de la escritura}

Leticia Cossettini fue una maestra que no sólo se dedicó a la transmisión de saberes, sino también a la escritura de su experiencia educativa. Dejó sus huellas pedagógicas impresas en dos libros, Teatro de Niños (1947) y Del Juego al Arte Infantil (1977), que fueron la materialización de un período en el cual la docencia significó para las mujeres una puerta de apertura hacia los espacios académicos reservados durante muchos años solo a los varones. Es cierto que, previo a la transición de siglos XIX y XX, la escritura se dio desde su origen como un mundo cerrado, exclusivo, un espacio masculino, ocasionalmente permeable a las mujeres. De tal forma, el acceso de las mujeres a la letra escrita se fue desarrollando de manera gradual. En América Latina, y más específicamente en el caso Argentino, ha sido de la mano del magisterio y del acceso a la alfabetización brindada desde la Ley de Educación Común N 1420 (año 1884), que las mujeres comenzaron un lento proceso de permeabilidad a la escritura impresa. Este "lento proceso" se debió principalmente a que ellas desobedecieron los mandatos sociales de la organización patriarcal. El binomio maestra-escritura se materializó no sin obstáculos. Al respecto Caldo (2018) sostiene:

\footnotetext{
La Ley de Educación Común 1420 (año 1884) estableció la legalidad de la educación obligatoria tanto para varones como para mujeres, oficializando la asistencia femenina. Sin embargo, que las mujeres asistan a las escuelas de primeras letras no fue un paso directo a los estudios superiores y al universo de la producción intelectual. Y aquí, en esta encrucijada que, por un lado, habilita lectura y la escritura, pero, por otro, obtura las posibilidades de producir conocimiento a partir de esos saberes, se juega una de las tensiones más palpables de la asimetría de género: leer y escribir sí, formarse como intelectual y profesional, no o no tanto (Caldo, 2018: 56).
}

En esta línea se encuentran los estudios de Graciela Batticuore (2005), quien ha realizado un estudio sobre la mujer escritora entre los años 1830 y 1870. Aunque el período temporal es anterior al que propone este artículo, esta literatura provee herramientas conceptuales para pensar la escritura femenina como producción cultural intermediada por lo público y lo privado. De acuerdo a Batticuore (2005) el "mandato de época" llevó a que diversas mujeres reprimieran su deseo de escribir a los fines de cumplir con el deber ser cultural femenino: el trabajo doméstico. Pero, sin dudas, otras, impulsadas por su vocación, buscaron "tácticas" (de Certeau, 1990: 43) para concretar la escritura propia: en el caso específico de las maestras, apropiándose del vínculo de la docencia con el mundo de lo doméstico.

Si bien desde la organización patriarcal se prescribió una sociedad con dos esferas bien demarcadas en "privada-femenina" "pública-masculina", ya son varios los escritos que demuestran de qué manera sus bordes manifiestan claroscuros y zonas grises. Justamente, lo que se 
prescribió como "límite" fue visto como táctica para muchas mujeres, convirtiéndola en "posibilidad":

Al menos en Argentina, las mujeres encontraron en el ejercicio de la docencia una posibilidad con sentido bifronte, por un lado, extender su rol doméstico a una institución pública, pero por otro, estudiar, trabajar, escribir, leer, percibir un salario, vivir solas (por los traslados) en fin, hacer uso de las herramientas de la vida pública e íntima, dos claves oficialmente negadas al género femenino (Caldo, 2018: 57).

Sin dudas no se piensa a Leticia, en su oficio de escritora, como un caso excepcional. En Argentina, como así en otros países, ha sido frecuente que mujeres en ejercicio docente vivenciaran la experiencia de la escritura. Algunas eligieron expresar sus ideas en periódicos de actualidad; otras optaron por la escritura de naturaleza militante, existieron quienes se inclinaron por la literatura, entonces poesías y cuentos fueron las formas que eligieron para expresarse. También estuvieron las mujeres que escribieron libros de corte pedagógico para sus colegas o bien de naturaleza didáctica como son los libros escolares destinados al estudiantado. Sin embargo, esta apertura al mundo de las letras no fue sin resistencias (Caldo, 2018). Las mujeres fueron conquistando espacios públicos a partir del juego pendular de la inclusión y la exclusión (Barrancos, 2002). En efecto, si a las maestras se les permitió escribir y luego publicar, no fue sin desestimar su pluma como un instrumento reproductor de "sus artes de hacer" (de Certeau, 1990). En el reparto de los roles sociales y específicamente se hace referencia aquí al rol docente, la enseñanza se perfiló dentro de las tácticas de los débiles. Sustraída del ámbito de producción de saberes científicos y abstractos, el trabajo docente se concluyó como un arte en donde se entramaron tácticas elaboradas por las maestras, las cuales, entendidas como parte de los sectores más desprotegidos, organizaron formas de resistencias y cuestionamiento a las embestidas del dominador. Por ello, repetitivas, domésticas, espontáneas, innatas, las prácticas docentes y/o áulicas están destinadas o bien, a no dejar huellas, o bien a no ser reconocidas.

Sin dudas, Leticia tejió y entretejió un sistema de tácticas que le abrieron las puertas al mundo editorial aunque como forma de transmitir su experiencia en la Escuela Serena específicamente. Esta particularidad de su escritura habilita a pensarla como maestra primero y escritora después, es decir, Leticia fue una maestra que escribió. En efecto, sus libros son la representación de "sus prácticas de enseñanza" a través del arte, una reproducción de sus clases, incluyendo diálogos, explicaciones, ejercicios, y demás reflexiones surgidas al calor de práctica en el aula.

A continuación, se pasará a analizar los dos libros de autoría de Leticia considerando que, mientras la Escuela Serena como programa institucional (Dubet, 2010) invisibilizó sus 
trayectorias que escaparon a lo propiamente áulico, ella desafió las estructuras escolares e incursionó por el mundo editorial.

Teatro de Niños. Este libro fue editado en el año 1947 por la Editorial Poseidón. Para ese entonces, Leticia ya contaba con nueve años de experiencia en las aulas. El libro está constituido por 72 páginas en las cuales se explayan, como una forma de espejo, los días de la maestra en ejercicio docente. Esta, durante años, fue registrando sus prácticas educativas por medio del uso de cuadernos de clases. Sin dudas, se presenta aquí un rasgo singular que refuerza la idea de pensar a Leticia como una maestra que escribía.

Los relatos escolares que se describen en el libro ya contaban con casi una década de existencia y, lo que se puede observar desde su escrito es que, más que proyectarse como escritora, lo hace como escribiente, entrampada en las lógicas de su rol y de la institución como única experiencia profesional. Diálogos, reflexiones, conceptos, explicaciones, pinturas en acuarelas y fotografías, se abren al juego en el Teatro de niños como una forma de "mostrar" las formas en que la Escuela Serena en general, pero Leticia en particular, incorporó el arte en la cotidianeidad de las clases. De esta forma, "la teoría" o "el rigor académico" que presentaba el libro estaba teñido por "marcas de experiencia" que se inscribieron en la Escuela y que Leticia registró para a posteriori publicar:

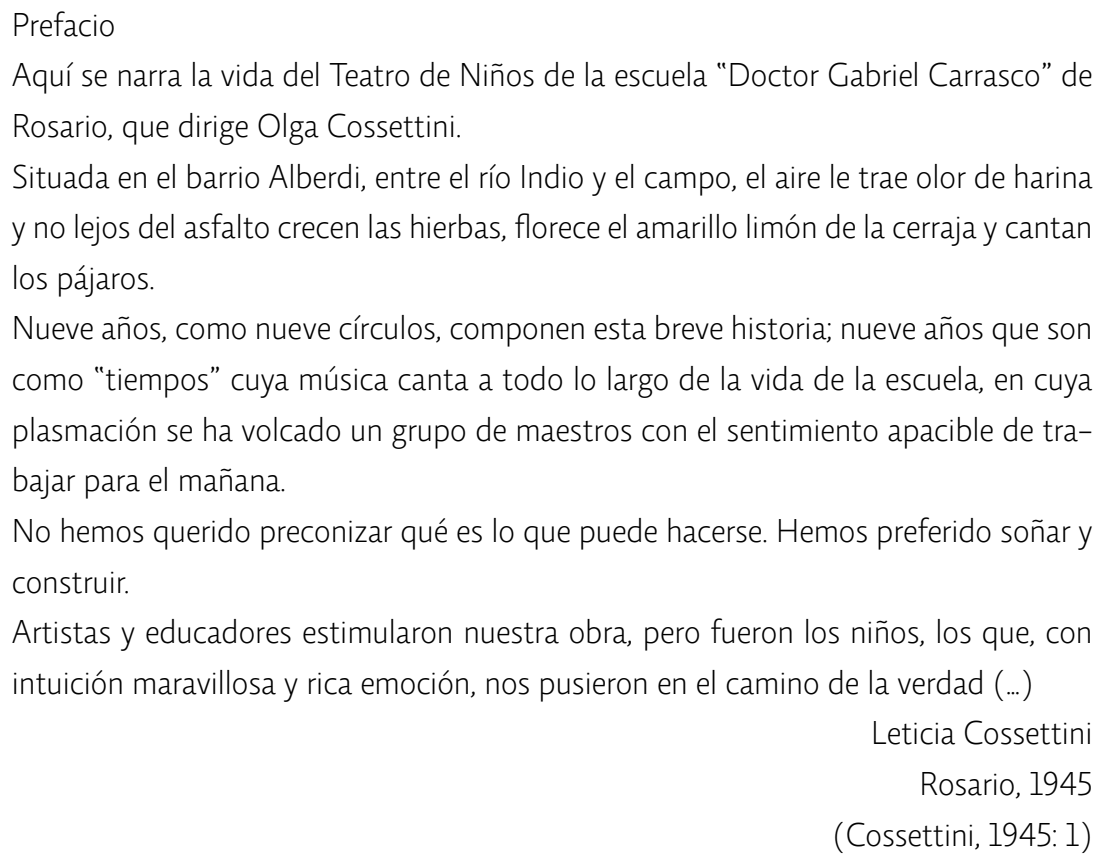

El libro relata experiencias que retratan estudiantes de ambos sexos con edades que oscilan entre los seis y los catorce años. En este caso, elaborar el texto implicó observar el modo de operar y aprender de sus alumnos y alumnas para luego proyectarlo en otros sujetos. Siguiendo 
a Leticia, se entiende que escribir un libro como "guía" para otras maestras o maestros, supone pensar que es una experiencia aplicable a otras realidades. Lo escribe claramente en su prefacio:

Si esta historia tan pequeñita que casi no se la ve, pero cuyo hálito se siente, consigue dar el mismo tono de gracia que fluye de las creaciones, de las impresiones, de las imágenes fotográficas y de los claros dibujos de los niños, sabremos que nuestros brazos tendidos hacia la luz se encontraran con los vuestros (Cossettini y Cossettini, 2001: 1).

La maestra, entonces, se ubica como ejemplo a imitar para otras docentes. Propone desde su libro métodos didácticos y prescripciones curriculares como herramientas que ayudarán y direccionarán las intervenciones de sus colegas.

Teatro de niños es un libro que relata una experiencia pedagógica con la intención de que sea imitada. Le pregunta del escrito gira en torno a la didáctica, es decir, el cómo el arte en general, pero el teatro en particular, fue implementado de manera transversal en la Escuela Serena. Demostrando, también, la recepción por parte de los y las estudiantes.

Leticia, durante sus nueve años como docente, siguió el consejo de Olga, su hermana directora, y dejó registrado en cuadernos de tapa dura, marca "Rivadavia", el desarrollo de sus clases. Estos, que hoy se pueden visualizar en el Archivo Pedagógico Cossettini (APC), fueron consultados advirtiendo que eran "la fuente" utilizada por la maestra para la publicación de su libro. Es decir, en los cuadernos que se registró la práctica de la docente se visualizaron los diálogos, las escenas, poesías y teatralizaciones que se presentan en Teatro de niños, empero en cada pequeño apartado, Leticia agregó además una breve introducción teórica. Fue en estas secciones del libro donde ésta demostró su principal participación en la proyección de una propuesta pedagógica atravesada por el arte.

La decisión de reproducir en el libro las prácticas educativas (aquí habla específicamente del teatro) pero también analizar sus implicancias subjetivas en el desarrollo del aprendizaje de sus alumnos y alumnas, demuestra que Leticia llevaba a cabo un proyecto "teorizado". Su ejercicio docente no fue, entonces, improvisación. Existía en ella un caudal epistemológico

\footnotetext{
${ }^{5}$ En otra oportunidad hemos escrito sobre estos cuadernos de uso frecuente en Argentina: "Este tipo de cuadernos fue fabricado por la imprenta de propiedad de Ángel de Estrada para uso escolar. Concretamente, en el año 1917, la marca lanzó al mercado hojas de papel. Sin embargo, cuando en 1920 se oficializó la implementación del cuaderno único, la empresa respondió en consecuencia, lanzando líneas de cuadernos, entre ellas los Rivadavia. Con el tiempo, el formato fue transformándose y, en esta lógica, para los años cincuenta ya estaban a la venta los de tapa dura como el que Leticia eligió para compilar sus recetas. Este soporte es representativo de la marca que lleva escrita en el centro de su portada en letra manuscrita cursiva, justo debajo de un escudo compuesto por una balanza rodeada por las siguientes palabras: "civilización, cultura, equidad, educación, ley, constitución". (Caldo y Pellegrini, 2019: 35)
} 
que justificaba ese accionar. Su saber-hacer resultaba, en definitiva, una enseñanza que, llevando sus rasgos de identidad, contenía un marcado principio pedagógico.

Caso similar fue su siguiente libro, Del juego al arte infantil. Este fue publicado cuando Leticia se encontraba fuera de su ejercicio docente: 1977. Para ese entonces, la maestra contaba con 27 años de pasividad en las aulas, guiño temporal que nuevamente se repite: esta mujer contó como única experiencia docente ${ }^{6}$ el proyecto de la Escuela Serena de Rafaela y como última la de Rosario.

En esta oportunidad, la editorial elegida por Leticia fue EUDEBA. Esta segunda publicación encuentra a una Leticia mayor con la necesidad de mostrar una vez más el legado de la Escuela Serena. Por eso, si bien conserva el carácter didáctico que contuvo el Teatro de niños, en Del juego al Arte Infantil se puede percibir una maestra que conserva una fuerte intención en dejar huellas de las experiencias vivenciadas en la Escuela Serena más que en producir saberes a partir de la misma. De hecho, en la primera página del escrito se puede leer la siguiente dedicatoria:

Introducción

"A mi hermana Olga":

Olga Cossettini dirigió la Escuela Experimental Dr. Gabriel Carrasco, desde 1935 hasta agosto de 1950. Escuela primaria situada en Rosario - Barrio Alberdi - en las proximidades del río, los huertos, y pequeños sembradíos y las avenías de acceso a la ciudad.

Los niños llegaban de la barriada pobre de pescadores y jornaleros, y la del comercio próspero, pequeñas industrias y viviendas cómodas entre arboledas y jardines. El hijo del pescador y el del obrero, el hijo del comerciante, del profesional, del hombre cultivado y sensible.

Era una escuela que aspiraba a hacer seres armoniosos, no poetas, ni artistas, ni pintores, ni músicos, ni mimos, no es desmedro del conocimiento y de la realidad tal como cierta anquilosada pedagogía expresaba su prevención frente a aquel testimonio vital.

[...]

Como modesto testimonio ofrezco páginas de mi "Diario de clase" que abarca el periodo comprendido entre 1936 y 1950, tiempo en el que fui maestra de alumnos que yo conducía desde el cuarto al sexto grado. Estas páginas traducen el clima de la escuela y en cierto modo, el espíritu de los maestros compañeros míos, que ayudaron con valor a la realización de una obra.

(Cossettini, 1977: 2)

\footnotetext{
${ }^{6}$ Sobre las actividades docentes llevadas a cabo por Leticia luego de su exoneración en la Escuela Serena, se ha podido constatar que desarrolló un curso de artes para niños y niñas (entre los años 50' y 60'). De acuerdo a una entrevistada (Entrevista Nº, realizada por Micaela Pellegrini Malpiedi, Rafaela, 2017), el curso era llevado a cabo en compañía de su padre en la vieja casona que los Cossettini aun mantenían en Rafaela. Era esta una actividad por fuera de los bordes del Sistema Educativo pero que, seguramente, se apoyaba en los principios escolanovistas.
} 
En la introducción de su libro, Leticia Cossettini realiza un resumen de lo que habría sido la Escuela Serena: el entorno, los alumnos y alumnas que asistían, el objetivo de su educación. A su vez, la dedicatoria para Olga demuestra la relación jerárquica que ambas mantenían. Si bien en las últimas líneas del apartado menciona el trabajo de sus colegas como instancia necesaria para la realización de la experiencia, es a Olga a quien, una vez más, se la reconoce como la responsable de la obra (Pellegrini y Mosso, 2017).

Por otro lado, la introducción deja claramente asentado de qué se trata el libro: es el acopio de los registros de clase que conservó en sus cuadernos de maestra. La publicación cuenta con 84 páginas que, estructuradas en tres capítulos, se constituye en un escrito destinado a docentes y demás interesados e interesadas en el campo de la educación.

De tal forma, al igual que en su libro anterior, los cuadernos de clase que se escribieron entre 1936 y 1950 son la fuente práctica de lo que Leticia a posteriori convierte en teoría. Aunque, en esta oportunidad, la puesta teórica no se hace presente, sino la escritura se centra más bien en el recuerdo, lo anecdótico, la descripción:

Entre las trayectorias de Leticia Cossettini por fuera de la docencia (aunque habilitada por ésta), se encuentra la escritura de libros. Pensar en esta práctica por los canales del mundo de lo público, invita a dialogar con una categoría conflictiva: la del intelectual. ¿Leticia puede ser pensada como tal? Hace trece años se atribuía esta categoría, únicamente, a los "grandes creadores de doctrinas" (Altamirano, 2008: s/p). Así, durante varias décadas, se desestimaba como intelectuales a varios personajes del mundo de la cultura y la ciencia que no encajaban con esta conceptualización. Reddy Williams (1982) ha sostenido que un intelectual es quien produce elementos dentro de la esfera de la ideología y la cultura. Por lo tanto, existen muchos actores sociales que, teniendo una práctica relacionada con la creación de conocimientos, posee determinadas tonalidades que no se ajustan con la estructurada conceptualización de la historia intelectual más clásica. Entre estos, se encuentran las mujeres, en primer lugar ( sólo por el hecho de serlo) y las maestras, en segundo (pensadas como agentes de Estado que ofician con autonomía, producción crítica y saberes de acción, pero desde los bordes del campo intelectual). Así, si se refiere al intelectual hegemónico, las maestras quedan por fuera de la conceptualización.

Existen distintos estudios que permiten interpretar a la escritura de las docentes dentro de las zonas grises que matizan las lecturas dicotómicas de las prácticas y de los saberes del Estado (Plotkin y Zimmermann, 2012a; 2012b). Son los estudios de Flavia Fiorucci ${ }^{7}$ (2013), los que ayudan a pensar a Leticia como "otra intelectual":

\footnotetext{
${ }^{7}$ Esta autora, junto a Laura Rodríguez, incluye a otros sujetos dentro de esta categoría analítica, advirtiendo "la idea de intelectual contextualizada espacial y temporalmente dentro del campo específico, entendido como una red o configuración de relaciones objetivas entre posiciones diferentes que ocupan los agentes e instituciones" (Fiorucci y Rodríguez, 2018: 10).
} 
[...] no siempre cumplen con las condiciones que normalmente la literatura identifica como propias de los intelectuales y/o de su labor, como haber logrado autonomía del poder político o eclesiástico, o participar de aquellos circuitos que se asocian a la idea de campo intelectual, como las revistas reconocidas de circulación nacional (Fiorucci, 2013: s/p).

Entonces, si se considera la inmutable labor productiva y creativa dedicada a la innovación en el plano de la enseñanza atravesada por el arte de Leticia; si se le reconoce como maestra de aula que concibió al arte como saber transversal; 8 si la pensamos como agente del Estado que trabajó por y para la transmisión de la cultura; si se la reconoce en la creación de vínculos con demás agentes de la misma, prescribiendo una enseñanza entrampada en intereses políticos, demostrando una idoneidad vocacional, y finalmente, como escritora, esta maestra fue una intelectual. No obstante, tratándose su pluma de una transcripción del acontecer áulico, de una reproducción de los diálogos, temarios, actividades de ese enseñar-haciendo perteneciente al rol docente, puede ser interpretada dentro del campo de "otros intelectuales" propuesto por Fiorucci (2018). Fundamentalmente, porque la puerta de apertura, de autoría, de negociación con empresas y agencias editoriales, de proyección profesional y pública que le brindó la docencia, Leticia lo hizo sin escapar de su rol de maestra.

Sin dudas, Leticia presentó como principal característica que, el punto de inicio de su producción editorial esté vinculada con "el hacer" de la práctica. Ese gesto la ubica dentro de la producción de saberes escolares (Terigi, 2007). De tal modo y volviendo al punto de partida de esta apartado, en la trayectoria de esta docente se puede visualizar la presencia de las artes de hacer (de Certeau, 1990) que, si bien, fueron entendidas peyorativamente, son un saber en sí mismo. Por lo cual, es pertinente situar a la escritura de Leticia, más que como producción de una intelectual, como producción de una maestra.

Son los estudios de las mexicanas Luz Elena Galván Lafarga y Lucía Martínez Moctezuma (2017) los que auxilian para pensar esta faceta de Leticia. Las autoras estudian a maestras que escriben, atribuyéndoles el concepto "escritoras didácticas". Esta asignación se aplica a:

Aquellos autores de libros de texto que ilustraban sus obras con ejemplos y explicaciones, conforme al orden de la materia, entendido como la forma más próxima a la que emplearía oralmente un buen maestro (Galván Lafarga, 2017: 68).

De tal forma, estudiar a Leticia como escritora didáctica permite observar esa relación pendular que la maestra desarrolló con la Escuela Serena. La menor de las Cossettini logra

\footnotetext{
${ }^{8}$ Este término es tomado de las propias palabras de Leticia Cossettini.
} 
romper con las lógicas de la institución moderna y trascender por trayectorias que escapan a lo que la forma escolar demanda para el rol docente. Sin embargo, esa trayectoria no es posible sin su anclaje en la experiencia escolanovista.

\section{Leticia Cossettini y su trayectoria en el campo de las artes}

Las huellas que referencian los trayectos de Leticia en el arte son escasas. Si su tarea como escritora fue desdibujada por el programa institucional moderno, su rol como artista fue menospreciado también porque su sensibilidad femenina no se correspondía con el canon (Mayayo, 2003).

Leticia fue una mujer que se desarrolló activamente en el campo del arte, pero sus notas artísticas traspasaron los límites de la Escuela Serena, resultando difícil "encasillarla" en un único género: fue autora de cuadros en acuarelas, coreografías musicales, títeres, diseños de ropas, pero su mayor distinción la obtuvo con la realización de figuras con chala del maíz:

\footnotetext{
No sé si eso del arte tiene algún otro componente porque la verdad es que ella hacía una síntesis de la música, de la danza, de la poesía, ¿a quién se le ocurre las figuras de chala?..., después ya cerca del final de su vida hizo esas lechuzas con incrustación de materiales, eso era muy original pero dentro de todo está vinculado con cierta forma de cultura contemporánea... ¿Pero la chala?, ja quién se le ocurre!... (Entrevista N³ realizada por Micaela Pellegrini Malpiedi, Rosario, 2016).
}

Resulta posible percibir dos momentos bien marcados en la relación de Leticia con la decisión de hacer públicas sus piezas de arte. En un primer momento, inmediatamente luego de haber sido exonerada (y jubilada) de la docencia, esta se abocó a la actividad creadora como necesidad económica:

\footnotetext{
Leticia se fue de la escuela aunque no la echaron, creo que gozó del privilegio de la jubilación extraordinaria, a los 40 o 46 años. Y allí empezó una nueva vida intentando desarrollarse como artista, hacía cosas de tipo arte plástico. Si ves esas dos figuras que están detrás de vos vas a poder ver dos esculturas hechas por Leti (Entrevista $\mathrm{N}^{\circ} 2$ realizada por Micaela Pellegrini Malpiedi, Rosario, 2015).
}

Si bien no se han encontrado indicios acerca del mercado que Leticia podría haber realizado con sus producciones, sí se han encontrado referencias de su trayectoria dentro del arte en dos publicaciones. Una de ellas, citada en una revista de Rosario (Santa Fe) específica del arte y la otra en un periódico de Buenos Aires. En ambas se dan a ver las figuras de chala. 
Concretamente en 1952 en la Revista ARS - Revista de Arte junto a publicidades en las que se ofrecían muebles, electrodomésticos, aerolíneas y productos alimenticios, se asoma una nota escrita por Bernando Canal Feijoo que lleva por título "Las figurinas de Leticia". El escrito tenía por cometido mostrar a un lector o lectora en vínculo con el arte, las producciones que una mujer realizaba con las cortezas desechables de la chala. En relación a las creaciones de Leticia, Canal Feijoo escribía:

La forma no cristaliza ídolos, iconos, en su arte; suscita una especie de mitología inaprehensible y fugaz, sirve como instancia de puro animismo [...] y en este sentido, está más cerca del arte supersticioso del "primitivo" que del arte estético del artista (Canal Feijoo, Revista ARS, 1952: s/p).

Fotografías de las figuras en chala de Leticia. Revista ARS "Revista de Arte"

Tal como lo describe el autor y como las imágenes que acompañan el escrito, se observan figuras humanas realizadas con un material original, cuya maleabilidad le permitió a Leticia otorgarle no sólo forma sino además movimientos. Las figurinas, llevan por nombre Caricia, Viento y Turbación.
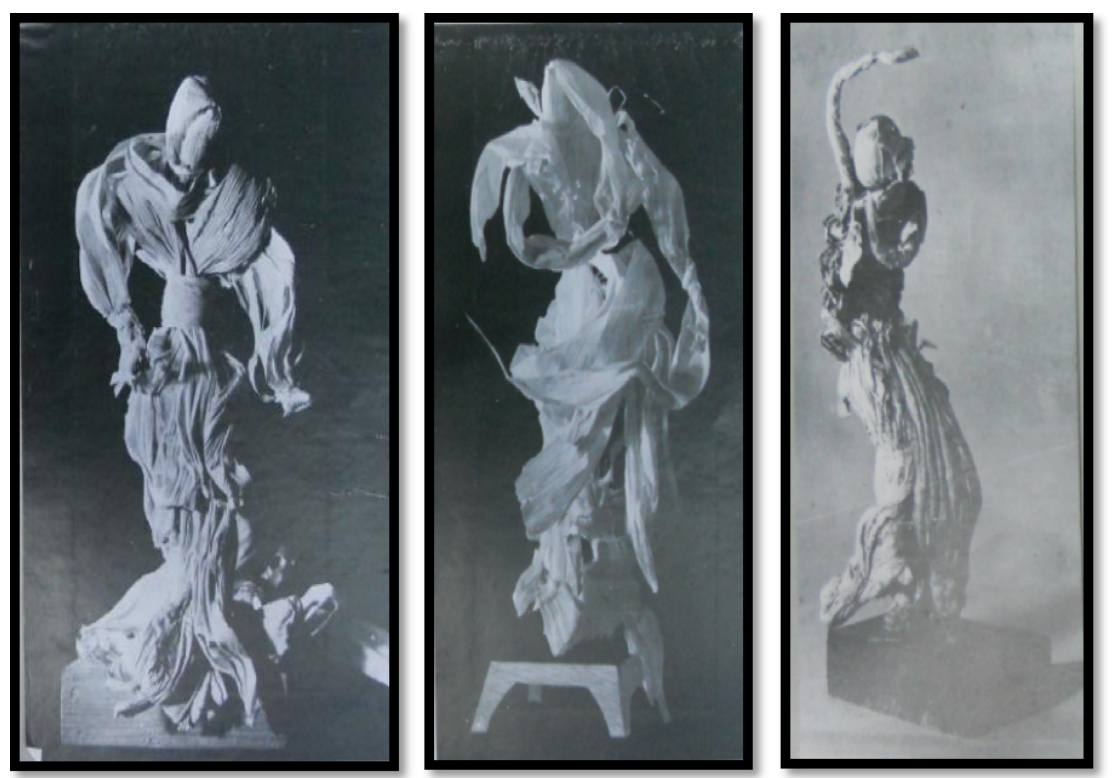

De acuerdo al autor, consideradas de origen mitológico o más bien "primitivo", las figuras de chala se alejan de las manos creadoras para ser interpretadas como un arte supersticioso perteneciente a una mujer más que el arte estético del artista. De este modo, hay una diferenciación entre "un artista" y "una mujer". Sin embargo esta subestimación no fue una singularidad del trabajo de Leticia, sino una práctica reiterativa para aquellas mujeres que 
quisieran incursionar en la materia de lo artístico. La historia de Leticia es, en términos generales, la historia de muchas otras artistas:

Nunca hablamos de hombres artistas o del arte de los hombres; hablamos simplemente de arte o de artistas [...] esta oculta prerrogativa sexual se basa en la creación de un contrapunto negativo, de un "otro", lo femenino, que funciona como el término necesario de comparación (Pollock, 2013: s/p).

La historia feminista del arte permite estudiar a las mujeres como creadoras y como objetos de inspiración. De acuerdo a estos estudios, el acceso al área de las bellas artes ha sido, para las mujeres, entorpecedor, opresivo y desalentador. El texto iniciático que dio cuerpo al análisis del arte y las mujeres fue escrito por Linda Nochlil (1971), quien en la década del 70’ se preguntaba ¿Por qué no ha habido grandes mujeres artistas? (Nochlin, 1971). La profesora advierte que, hasta ese momento y desde la historia del arte, se incitó la búsqueda de artistas mujeres con la finalidad de biografiarlas y demostrar cómo las mujeres también participaron de la actividad creadora. Si bien este primer ejercicio fue necesario para visibilizar la presencia femenina en los centros del arte, no resultaba suficiente en tanto las biografiadas eran, en su mayoría, artistas que se "ajustaron" al canon masculino. Precisamente, lo que Nochlil (1971) cuestiona es el ¿por qué?, para proveer de un análisis social, cultural, institucional, que dé cuenta sobre los motivos que excluyeron a las mujeres del canon.

Para Nochlin, "la culpa" hay que buscarla en las instituciones, en las escuelas. Sostiene, la "educación entendida como todo aquello que nos ocurre desde el momento en que llegamos a este mundo de símbolos, signos y señales cargados de significados" (Nochlin, 1971: 284). De este modo, el arte es considerado como una carrera de obstáculos para las mujeres, poniendo el foco en las trabas institucionales: por ejemplo la imposibilidad de acceder a las academias o escuelas públicas, la inexistencia de becas, la dificultad por acceder a espacios públicos, etc. Sin embargo, años más tarde, otra intelectual en la materia, Greer (1970) viene a cuestionar la teoría de Nochlin. La autora advierte que las verdaderas limitaciones residían más bien en la internalización de una sumatoria de prejuicios que la sociedad esgrimía sistemáticamente sobre las mujeres.

De este modo, así sea por factores externos institucionales o factores internos inconscientes, la academia coincide en que diversos mecanismos se constituyeron como una barrera de acceso para las mujeres al mundo artístico. En este sentido, no resulta llamativo que el paso de Leticia por los canales del arte no haya sido reconocido. Si bien es cierto que esta mujer nació en los primeros años del siglo XX, cuando la situación de las mujeres y el mundo artístico ya habían dado sus primeros pasos (hasta el siglo XIX habían sido mayoritariamente excluidas de las escuelas u organizaciones especializadas en la formación artística), 
Leticia debió enfrentar también los mecanismos de invisibilización institucionales por partida doble: en tanto mujer y en tanto maestra.

Aquí es posible citar a Mayayo (2003) quien explicita cómo las nociones atribuidas "a lo femenino" en el siglo XIX fue influyente a la hora de percibir el arte femenino, desde ese entonces hasta la actualidad. La artista sostiene que, al constituirse el ideal de mujer doméstica como "el ángel del hogar" también se afianzó, en materia artística, lo que se llama doctrina de las esferas separadas. Surge así, un arte hegemónico (reservado a los varones) y un "arte femenino": grácil, delicado, sensible. Como sostienen Rozsika Parker y Griselda Pollock (1981), todo lo que las mujeres producen se mide en función a su pertenencia al sexo femenino, designación que las ubica, al mismo tiempo, en un status secundario como autoras. En relación a esto, el canon se trata de una construcción histórica-artística-institucional basado en la jerarquía de grandes hombres y "otros segundones" (Mayayo, 2003). Se configuró un modelo de "genio", una genialidad artística basada en la retórica de la exclusión: esto es, energía, vigor sexual, fuerza. Es decir, todos atributos masculinos. Imperativos descriptivos que dejan por fuera a las mujeres, exigidas por entonces a ser dulces, sensibles, morales, decorosas.

Estas dos esferas, que hacen alusión a un arte propiamente dicho y a un arte femenino, habilitaron la creación de una autoridad universal basada en las nociones de grandeza y logro artístico definidos de modo masculino. Surgió, entonces, un discurso categórico acerca de un "artista profesional" y otro "aficionado". El primero es definido tácitamente como un hombre de clase media cuyo trabajo y habilidad le reporta un alto status. El segundo, por cierto, refiere a todos aquellos sujetos que utilizan al arte como modo "accesorio" o "hobbies" de los momentos libres. Justamente las mujeres, en su rol como amas de casa, madres, esposas, eran quienes "encajaban" con esta segunda conceptualización. Una conceptualización cuyo objetivo era cuestionar el valor de otras identidades artísticas: mujeres, negros, pobres, etc. (Mayayo, 2003).

Leticia fue partícipe de un momento histórico singular si se piensa en el mundo artístico. De la mano de la masividad educativa propuesta desde Sarmiento y la creación de las escuelas normales, dotó a las mujeres de fines del XIX y principios del XX de posibilidades para sumergirse en las sendas culturales, intelectuales y artísticas anteriormente vedadas (Cluzman, 2015). En este sentido, durante estos años las femeninas comenzaron a ingresar a los círculos artísticos. Sin embargo, esta entrada no fue sin el reforzamiento de discursos en torno a la diferencia sexual, productora de una supuesta divergencia natural y automática en la creación artística. En correspondencia con esto, Leticia fue una mujer del siglo XX que estudió, trabajó y dedicó su vida a las manifestaciones del arte empero sin hacer públicas sus producciones. Su profesión docente le habilitaba el espacio para poder desarrollar su perspectiva artística pero siempre dentro del aula. Fue por eso que recién en la década del 50’ y una vez 
fuera de la escuela, decidió socializar sus producciones. Sin embargo, en "ese mostrar" se encontró con que sus piezas de arte eran analizadas a partir de los mismos significantes que se les atribuyeron a otras mujeres artistas. Sus figuras de chala fueron interpretadas no como producto de una práctica rigurosa, de un espíritu creativo, de la interiorización de un marco teórico, sino como el resultado de un movimiento mágico, amateur, aficionado. Canal Feijoo, se condice con lo explicitado en las últimas líneas:

La esencia de este arte intaxativo de Leticia Cossettini, ese arte intaxativo que tiene de escultura, de juguetería, de mitología, es así mágica. Es arte idéntico a su teoría, pero una teoría que nada tiene de normativa y abstracta, que es en sí, por sí misma, descubrimiento, no está antes de la experiencia en que se prueba. Esa teoría que comienza con cierta vivencia de la forma que se tienta y que no está designada a la perduración como forma (Canal Feijoo ARS, 1952: s/p).

Si bien Leticia no cursó los estudios en Bellas Artes, sí fue una mujer que no estuvo al margen de las ideas modernas de los artistas, ni tampoco consideraba sus creaciones como "meros adornos". Su vida completa estuvo dedicada al consumo y la producción de arte. Todo su capital cultural, percibido desde muy pequeña, le atribuyó un gusto distinguido acerca de las manifestaciones artísticas. Por lo cual, luego de tantos años de escuchar música clásica, de visitar galerías, de leer literatura acerca de la teoría del arte, de desarrollar una propuesta educativa con una centrada connotación hacia lo estético, Leticia volvió a socializar sus objetos de arte y un periódico de Buenos Aires lo difundió.

Sus figurinas de chala también fueron título en el Diario Clarín (s/f) (APC). Un artículo titulado "La magia de la Chala y la Corteza" anoticiaba que las figurinas de la maestra se encontraban exhibidas en la Galería Alcorta. El contenido del escrito es el mismo que el publicado en la Revista ARS y se trata del mismo autor. Nuevamente, la decisión de exhibir sus obras y su presencia en los canales oficiales del arte deja sentado que la maestra jubilada expresa sus deseos de ser vista como mujer comprometida con el desarrollo del arte y no como "aficionada". Indudablemente, siendo jubilada es cuando da el gran paso de aquella maestra que enseñó a sus alumnos a ser sensibles a partir del arte, a esta otra mujer, ya despojada de su labor docente y que decide exponer sus producciones artísticas.

Sin embargo, en el cuerpo del texto del artículo periodístico, resultaba inverosímil separar sus producciones de su "esencia femenina". En relación a esto, Gluzman (2015) es quien realiza una meticulosa investigación sobre el discurso que los críticos del arte desarrollaron hacia las creaciones femeninas de fines del XIX y comienzos del XX. Estas siempre fueron presentadas regularmente, vinculadas al campo semántico de la delicadeza, recurrencias que constituyeron unos de los tópicos más evidentes de la valoración que la historia del arte ha hecho de las mujeres artistas, cuyo estilo es siempre introspectivo, delicado y sutil: 
Realmente le gustaba hacer, trabajar la chala. Lástima que no has visto las cosas jno están! Porque se las han llevado, yo no sé si las sobrinas, las figuras de chala, json una belleza! El que las tiene, si las conserva, estaban en buen estado, van a estar por mucho tiempo; le gustaba hacer cerámica también, pero sobre arte... bueno ya solo con verla, la presencia, la figura de ella, vos decís esta mujer es artística; esta mujer tiene una belleza... algo ya de sí misma, con solo mirarla nada más (Entrevista $\mathrm{N}^{\circ} 1$ realizada por Micaela Pellegrini Malpiedi, Rosario, 2015).

Si bien, la cita aquí transcripta no corresponde a la de un crítico de la historia del arte, sí es el relato de una amiga de Leticia. Esta demuestra cómo determinadas creaciones desarrolladas por mujeres (no necesariamente se alude a las artísticas) tuvieron reconocimiento público en tanto encajaban dentro de lo que es entendiendo como "femenino". Leticia realizaba figuras de chala y manifestaba producciones artísticas en tanto fue una mujer bella, sensible, con un cuerpo maniobrado por los sentimientos, el decoro, la magia. Adjetivaciones personales que desembarcan en sus creaciones y que presentan como objetivo la descalificación de las mismas.

La lógica escolar del proyecto institucional moderno (Dubet, 2010) se encuentra tan arraigado al momento de singularizar a los sujetos que en él se desenvuelven que, en el APC, solo se cuenta con estas dos publicaciones que referencian a la trayectoria de Leticia dentro del campo de las artes. Sin embargo, consultando más centros documentales como así entrevistando a sus allegados, se advirtió que Leticia experimentó un segundo momento en relación a la exhibición de sus obras. Será recién en el año 2000 cuando, octogenaria, presenta en público otra de sus producciones artísticas: sus pinturas en acuarelas:

Al tiempo que fallece Olga, era visitada por Rubén Naranjo, a quien un día se le ocurrió mostrarle uno de sus cuadros. Cuando los vio organizó él una exposición en el Castagnino. Acá tengo dos en casa, que me regaló, y mi hija uno... era una cosa bastante tapada. Era su gusto haberlos hecho pero no le daba importancia (Entrevista N4, realizada por Micaela Pellegrini Malpiedi, Rosario, 2017).

En efecto, Leticia se permitió volver a interactuar en el campo del arte como productora y no como una mera consumidora, una vez aconsejada por un reconocido pintor argentino: Rubén Naranjo.

Para analizar este segundo momento en la vida de Leticia, es elocuente citar a Virginia Woolf (1995), quien pone en palabras la necesidad de un cuarto propio para la producción artística. En el caso de Leticia, su cuarto propio no fue más que el espacio que separaba el colchón de su cama con el ras del suelo: 
Cuando Olga fallece, Leticia decide donar todo un caudal de materiales para hacer el archivo de la Escuela, entre esos materiales me muestra un baúl Ileno de cuadros propios, estaba debajo de su cama. Me contó que nunca los mostró porque le habían dicho que no eran muy buenos, por lo tanto que no se dedique a ello (Entrevista $N^{\circ} 4$ realizada por Micaela Pellegrini Malpiedi, Rosario, 2017).

Esta maestra, que desarrolló una propuesta educativa centrada en lo estético, solo pudo reconocerse como una artista y recorrer los trayectos que las prácticas del arte establecen, una vez jubilada. Las lógicas escolares exigen un rol docente en el cual, las manifestaciones de los rasgos subjetivos están vedadas. Por lo cual, la sensible y etérea Leticia solo pudo socializar sus producciones artísticas cuando fue exonerada y perdió referencia institucional con la Escuela Serena. Sin embargo, esta antes de ser maestra fue mujer y, en ese sentido, sus objetos de arte fueron valorados peyorativamente. Así fue como pasó de un significativo reconocimiento de su trabajo artístico dentro del aula a una desestimación de sus producciones por fuera de la escuela.

Aún en la segunda mitad del siglo XX y comienzos del siglo XXI, diversos discursos, factores sociales e institucionales habrían impedido que su talento se desarrollara libremente. Su situación personal se remonta a las líneas de investigación de Greer (1970), quien reflexionó sobre la internalización, por parte de las mujeres, del canon masculino, sistema de valores y símbolos que las dejaron por fuera de la creación artística. ¿Habrá sido la descripción que recibió sobre sus figuras de chala la punta del ovillo de su subestimación?, ¿cómo ser quien realmente se desea si los intersticios de la cultura esperan un estereotipo femenino diferente a su yo?

Sin embargo, la exclusión de Leticia en el mundo del arte también se correspondió con las características de sus acuarelas: pinturas de naturaleza muerta, flores, frutas y a veces paisajes. De acuerdo a Mayayo (2003), durante el siglo XIX, dentro del canon se establecieron géneros "menores" en la pintura. Así, el retrato, el paisaje o la naturaleza muerta, se constituyeron como los propicios para el cultivo de las mujeres.

Los ramilletes de flores o las fuentes con frutas dibujadas por Leticia, hoy se encuentran dispersas por las viviendas de sus seres allegados. Todos y todas las entrevistadas han manifestado contar en sus hogares con una pieza única de su amiga. En este sentido, lejos de los museos, galerías, academias, o libros de arte, los cuadros de Leticia ocuparon un lugar privilegiado en los ámbitos domésticos de su entorno social: livings, comedores, salas de estar, escritorios, fueron los lugares predilectos para agasajar a la artista. 
Finalmente, fue en el siglo XXI que Leticia, apadrinada por Rubén Naranjo, toma la decisión de exponer sus obras, no en el espacio privado de los hogares de sus seres cercanos, sino en una exposición en el Museo Castagnino de la ciudad de Rosario:

Practicó sobre todo la acuarela, y creo que fue Rubén Naranjo - el gran Rubén Naranjo - asombrado tras una inesperada demostración de un acopio de pinturas guardadas casi en secreto, quién promovió una exposición en el Museo Costagnino, en la época en que Fernando Farina era el director, que se inauguró el 29 de noviembre del 2002, y que provocó el asombro de muchos (Entrevista $N^{\circ} 4$ realizada por Micaela Pellegrini Malpiedi, Rosario, 2017).

Lo que interesa de este suceso en la vida de Leticia, es que, como muchas otras mujeres (y maestras), practicó la pintura en acuarelas desde la oscuridad, el silencio, el secreto. Se puede asumir que esta actitud se vincula con su búsqueda por "encajar" en los estereotipos de mujer y de mujer maestra. En primer lugar, como mujer se ha podido constatar de qué manera durante muchos años no estuvo "bien visto" que las mujeres sean artistas. Entonces aquí, su trayectoria en el campo del arte resulta un elemento de su antibiografía, en tanto se vio obstaculizada por el contexto. En segundo lugar, como maestra, es acertado pensar en una Leticia entrampada en las estructuras de la forma escolar moderna. Sin duda alguna, ser artista resultaba un elemento que escapaba a los valores y prescripciones exigidos por el programa institucional moderno.

\section{Reflexiones finales}

Si bien existe una cuantiosa bibliografía que referencia a la vida de Leticia Cossettini, la misma lo hace pensándola como parte del movimiento escuela nueva e inscripta dentro de la lógica institucional moderna (Dubet, 2010) de la Escuela Serena. En este sentido, el reconocimiento que se hace hacia la mujer es en tanto fue maestra, dejando en un cono de sombra aquellos roles desarrollados por fuera (aunque si relacionados) de la enseñanza. En este sentido, se trabajó como "la Leticia maestra", lo cual ocultó parte de su agencia y de su ejercicio por fuera de las aulas. Cuando François Dubet (2010) explica que el programa institucional moderno alude a jerarquías, asimetrías y roles que al tiempo que respaldan la autoridad y el hacer docente, supeditan sus singularidades biográficas a los roles instituidos. En este sentido, la particularidad de los maestros y las maestras queda reducida a sus quehaceres escolares. En otras palabras, todas son "la señorita", sólo distinguida por su nombre de pila y el grado. Sin embargo, a medida que se iban corriendo los efectos antibiográficos 
que operaron sobre su singularidad en tanto maestra, aparecieron aquellos otros que actuaron de igual modo en tanto escritora y artista.

Finalmente, desde este artículo, se propuso reconocer el aspecto versátil de Leticia que ha quedado oculto detrás de su guardapolvo blanco e invita a pensar en las trayectorias de vida de otras maestras que también han sido escondidas detrás de su profesión, aunque en el transcurso del trabajo investigativo resulte frecuente encontrarse con nuevos efectos antibiográficos relacionados ahora por el rol estereotipado de "ser mujer".

\section{Fuentes}

Entrevista $N^{\circ} 1$, realizada por Micaela Pellegrini Malpiedi, 2015, Rosario.

Entrevista $N^{\circ} 2$, realizada por Micaela Pellegrini Malpiedi, 2015, Rosario.

Entrevista N³, realizada por Micaela Pellegrini Malpiedi, 2016, Rosario.

Entrevista N4, realizada por Micaela Pellegrini Malpiedi, 2017, Rosario.

Entrevista N6, realizada por Micaela Pellegrini Malpiedi, 2017, Rafaela.

Revista ARS, 1952 (APC)

Diario Clarín, s/f (APC)

\section{Bibliografía}

Altamirano, Carlos (2008), Historia de los intelectuales en América Latina I. La ciudad letrada, de la conquista al modernismo. Katz. Argentina.

Barrancos, Dora (2002), Inclusión/Exclusión. Historia con mujeres. Fondo de Cultura Económica. Buenos Aires.

Batticuore, Graciela (2005), La mujer romántica: lectoras, autoras y escritores en la Argentina, 1830-1870. Edhasa. Buenos Aires.

Billorou, María José (2016), "Mujeres que enseñan no sólo en las aulas. Docentes en el interior argentino en la primera mitad del siglo XX" en Caldo, P. y Vignoli, M. Dossier (Parte I): Maestras, prácticas, género e historia: hacia una historia de la educación con mujeres en los tiempos de la consolidación de los sistemas educativos. En Anuario, Buenos Aires.

Caldo, Paula (2018), "Tizas y apuntes: costumbres en común. Maestras, libros y prácticas de la enseñanza en Argentina de 1930" en Fiorucci, F. y Rodríguez. L. (comp.) Intelectuales de la educación y el Estado: maestros, médicos y arquitectos. Universidad Nacional de Quilmes. Buenos Aires.

Caldo, Paula y Pellegrini Malpiedi, Micaela (2019) "Leticia cocinera. Repensando las prácticas cotidianas de una maestra argentina a partir de sus notas culinarias (1904-2004)" en Cuadernos de Historia Cultural $N^{\circ} 8$, Viña del Mar.

Carli, Sandra (2002), Niñez, pedagogía y política. Transformaciones acerca de la infancia en la historia de la educación argentina entre 1880-1955. Miño y Dávila Editores. Buenos Aires.

Castells, María del Carmen (2008), "Olga Serena y la Escuela Serena de Rafaela. Disrupciones en una experiencia” en Castells, María del Carmen; Migueles, María Amelia y Corfield, María Isabel, Didáctica y pedagogía. Trayectorias y movimientos. Un análisis de la configuración del campo de Entre Ríos y Santa Fe (1915-1930). UNER. Entre Ríos. 
Colotta, Pablo (2002), "Escritura y poder en la escuela nueva argentina" en Cucuzza, Héctor y Pineau, Pablo, Para la historia de la enseñanza de la escritura en Argentina: del catecismo colonial a la Razón de mi vida. Miño y Dávila Editores. Buenos Aires.

Cossettini, Leticia (1947), Teatro de niños. Poseidón. Buenos Aires.

Cossettini, Leticia (1950), Del juego al arte infantil. EUDEBA. Buenos Aires.

Cossettini Olga y Cossettini, Leticia (2001), Obras Completas. AMSAFE. Rosario.

de Certeau, Michel (1996), La invención de lo cotidiano. I Artes de hacer. Universidad Iberoamericana. México.

Díaz, Javiera y Serra, María Silvia (2009), "Olga y Leticia Cossettini: ¿maestras, mujeres e intelectuales?" en Educación, Lenguaje y Sociedad Vol. VI Nº.

Dubet, Francis (2010), "Crisis de la transmisión y declive de la institución" en Política y Sociedad, Vol. 47 Núm. 2: 15-25.

Fernández, María del Carmen; María Elisa Welti, Rubén Biselli, María Eugenia Guida (2014), Olga y Leticia Cossettini en la Escuela Serena. Cultura, imagen y pedagogía (Rosario 1935-1950). Laborde Editor. Rosario.

Fernández Sandra y Caldo Paula (2013), La maestra y el museo. El ombú bonsái. Rosario.

Fiorucci, Flavia (2013), "Presentación. Dossier: los otros intelectuales: curas, maestros, intelectuales de pueblo, periodistas y autodidácticas", en Prismas, revista de historia intelectual, núm. 17, pp. 165-168.

Fiorucci, Flavia y Rodríguez. Laura (comp.) (2018). Intelectuales de la educación y el Estado: maestros, médicos y arquitectos. Universidad Nacional de Quilmes. Buenos Aires.

Galván Lafarga, Luz Elena y Moctezuma Martínez, Lucía (2017), "Dos maestras: María M. Rosales y Ana María Valverde, autoras de la colección de lectura Rafaelita" en, Galeana, Patricia, Maestras urbanas y rurales, siglos xix y xx. "Colección: las maestras de México Vol. 3". México: Secretaría de Cultura, Instituto Nacional de Estudios Históricos de las Revoluciones de México.

Gluzman, Georgina, (2015), "Mujeres y Arte en la Buenos Aires del Siglo XIX: Prácticas y discursos", Vol. I. Tesis presentada con el fin de cumplimentar con los requisitos finales para la obtención del título Doctor de la Universidad de Buenos Aires en Artes, Buenos Aires.

Greer, Germaine (1970), The Female Eunuch. Letters to the Editor. Reino Unido.

Mayayo, Patricia (2003), "En busca de la mujer artista" en Historias de mujeres, historias del arte. Cátedra. Madrid.

Morgade, Graciela (1995), "Mujeres y educación formal: de la lucha por el acceso a la lucha por el currículum" en Propuesta educativa. Miño y Dávilas. Buenos Aires.

Nochlin, Linda (1971), ¿Why There Have Been No Great Women Artists?, s/r.

Parker, Rozsika y Pollock, Griselda (1981), Old Mistresses, Women, Art and Ideology. Pandora. London.

Pelanda, Marcela (1995), La escuela activa en Rosario. La experiencia Cossettini. IRICE. Rosario.

Pellegrini Malpiedi, M. (2016), "Sensibilizar cuerpos para trabajar, sensibilizar cuerpos para consumir: la Escuela Nueva santafesina, Rosario, 1935-1950" Cartografías del Sur, año 2, n 4, pp. 137-159, Avellaneda.

Pellegirni, Malpiedi, M. y Mosso, Agustina (2017), "Entre hermanas - entre mujeres: la vida cotidiana de Olga y Leticia Cossettini, Argentina, 1950 y 1980? en Arenal. Revista de Historia de las Mujeres Vol. 24, Murcia.

Pellegrini Malpiedi, Micaela (2019), "Archivar, conservar, mitificar y profanar... criterios de conservación que obstaculizan la tarea" en de Paz Trueba, Yolanda; Caldo, Paula y Vassallo, Jaqueline, Actas de las IV jornadas de investigación y reflexión sobre historia, mujeres y archivos. Instituto de Geografía, Historia y Ciencias Sociales (IGEHCS) Universidad Nacional del Centro / CONICET. Tandil. 
Plotkin Mariano y Zimmermann Eduardo (2012a), Las prácticas del Estado. Política, sociedad y elites estatales en la Argentina del siglo XX. Edhasa. Buenos Aires.

Plotkin Mariano y Zimmermann Eduardo (2012b), Los saberes del Estado. Edhasa. Buenos Aires.

Pollock, Griselda (2013), Visión y diferencia. Feminismo, feminidad e historias del arte. Fiordo. Buenos Aires.

Puiggrós, Adriana (dir.) (1993), Historia de la educación en la Argentina. La educación en las provincias y en los territorios nacionales. Galerna. Buenos Aires.

Reddy, Williams (2001), The navigation of feeling: A framework for the history of emotions. Cambridge University Press. Cambridge.

Terradas, Ignaci (1992), Eliza Kendall. Reflexiones sobre una antibiografía. Barcelona: Publicaciones de Antropología Cultural, Universidad Autónoma de Barcelona. Barcelona.

Terigi, Flavia (2007). "Exploración de una idea. En torno a los saberes sobre lo escolar" en Baquero, Ricardo, Diker, Gabriela y Frigerio, Graciela (comp.) (2007) La forma de lo escolar. Del Estante Editorial. Buenos Aires.

Woolf, V. (1995). Una habitación propia. Barcelona: Seix Barral.

Yannoulas Silvia (1996), Educar: ¿una profesión de mujeres? La feminización del normalismo y la docencia (1870 - 1930). Kapeluz. Buenos Aires. 